\title{
Performance of a Helicon Hall Thruster Operating with Xenon, Argon, and Nitrogen
}

\author{
Adam Shabshelowitz* and Alec D. Gallimore \\ University of Michigan, Ann Arbor, Michigan 48109 \\ and \\ Peter Y. Peterson辛 \\ ElectroDynamic Applications, Inc., Ann Arbor, Michigan 48105 \\ DOI: $\underline{10.2514 / 1 . B 35041}$
}

\begin{abstract}
The helicon Hall thruster is a two-stage thruster that was developed to investigate whether a radio frequency ionization stage can improve the overall efficiency of a Hall thruster operating at high thrust and low specific impulse. This paper describes an experiment that measured the single-stage and two-stage performance of the helicon Hall thruster operating at $10-25 \mathrm{mg} / \mathrm{s}$ anode mass flow rates of xenon at 100-200 $\mathrm{V}$ discharge voltages, and also for $6 \mathrm{mg} / \mathrm{s}$ of argon at $300 \mathrm{~V}$, and $2.6 \mathrm{mg} / \mathrm{s}$ of nitrogen at $200 \mathrm{~V}$. The helicon Hall thruster performance during operation with argon and nitrogen is characterized by low beam divergence efficiency and low propellant utilization efficiency. During two-stage operation, the thrust of the helicon Hall thruster marginally increased with radio frequency power, but the propulsive efficiency and thrust-to-power both decreased with increasing radio frequency power. Probe diagnostics suggest that gains were realized by a slight increase in propellant efficiency, but that the rate of increase was not sufficient to overcome the increase in power.
\end{abstract}

\section{Nomenclature}

$A_{c, \text { eff }}=$ Faraday probe effective collection area, $\mathrm{m}^{2}$

$e^{\prime}=$ elementary charge, $\mathrm{C}$

$E_{1} \quad=$ voltage exchange parameter, -

$E_{2} \quad=$ mass exchange parameter, -

$\mathcal{F}=$ Faraday constant, $\mathrm{C} / \mathrm{mol}$

$I_{\text {axial }}=$ axial component of ion beam current, $\mathrm{A}$

$I_{\text {beam }}=$ ion beam current, A

$I_{c}=$ current collected by probe, $\mathrm{A}$

$I_{d}=$ thruster discharge current, $\mathrm{A}$

$I_{\mathrm{sp}, a}=$ anode specific impulse, $\mathrm{s}$

$\mathcal{M}=$ molar mass, $\mathrm{kg} / \mathrm{mol}$

$m_{i} \quad=\quad$ ion mass, $\mathrm{kg}$

$\dot{m}=$ total thruster mass flow rate, $\mathrm{kg} / \mathrm{s}$

$\dot{m}_{a} \quad=$ anode mass flow rate, $\mathrm{kg} / \mathrm{s}$

$\dot{m}_{c} \quad=$ cathode mass flow rate, $\mathrm{kg} / \mathrm{s}$

$P_{d} \quad=$ discharge power, $\mathrm{W}$

$P_{\mathrm{dc}}=$ dc discharge power, $V_{d} I_{d}, \mathrm{~W}$

$P_{\text {elec }}=$ total electrical power, $\mathrm{W}$

$P_{\text {mag }}=$ magnet power, $\mathrm{W}$

$P_{\mathrm{rf}}=$ radio frequency power, $\mathrm{W}$

$P_{\text {thrust }}=$ jet power of thruster exhaust, $\mathrm{W}$

$r=$ Faraday probe distance from thruster, $\mathrm{m}$

$T=$ measured thrust, $\mathrm{N}$

$v_{\text {axial }}=$ average axial velocity of exhaust particle, $\mathrm{m} / \mathrm{s}$

$V_{d}=$ discharge voltage, $\mathrm{V}$

$V_{\mathrm{mp}}=$ most probable potential of exhaust ions, $\mathrm{V}$

$V_{p}=$ plasma potential, $\mathrm{V}$

$\eta_{a}=$ anode efficiency, -

Presented as Paper 2012-4336 at the 48th AIAA/ASME/SAE/ASEE Joint Propulsion Conference \& Exhibit, Atlanta, GA, 30-1 August 2012; received 14 May 2013; revision received 9 July 2013; accepted for publication 2 August 2013; published online 13 March 2014. Copyright ( $\odot 2013$ by Adam Shabshelowitz. Published by the American Institute of Aeronautics and Astronautics, Inc., with permission. Copies of this paper may be made for personal or internal use, on condition that the copier pay the $\$ 10.00$ per-copy fee to the Copyright Clearance Center, Inc., 222 Rosewood Drive, Danvers, MA 01923; include the code 1533-3876/14 and \$10.00 in correspondence with the CCC.

* Graduate Research Assistant. Member AIAA.

${ }^{\dagger}$ Arthur F. Thurnau Professor of Aerospace Engineering. Fellow AIAA.

*Consultant; currently at Aerojet in Redmond, WA; peterson@ edapplications.com. Member AIAA.

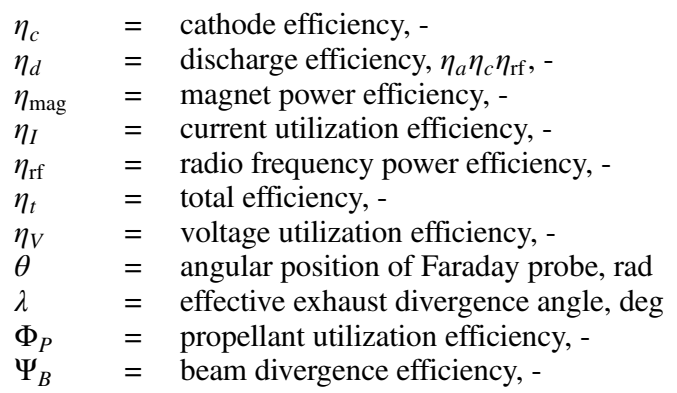

\section{Introduction}

$\mathbf{H}$ ALL thrusters were first employed in space by the former Soviet Union in the 1970s, but it was not until the early 1990s that significant Hall thruster development work occurred in the United States [1,2]. Current Hall thruster research activities primarily focus on improving thruster lifetime [3] , using propellants other than the traditional xenon $[4,5]$, increasing the power and thrust density $[6,7]$, and extending the range of performance [8,9]. The success seen by many of these research efforts show that Hall thrusters are a robust and versatile technology.

Helicon plasma sources have been studied since the 1960s, with early studies focusing on their ability to efficiently produce highdensity plasma for materials processing $[\underline{10}, \underline{11}]$. Since that time, a considerable amount of development work toward using helicon sources in electric propulsion systems has been performed. Some of this work involves the use of a helicon source alone as a thruster [1215], whereas other propulsion systems attempt to use the helicon source as an ionization stage, with a separate acceleration stage [16-18].

Electrostatic thrusters rely on electron bombardment processes to ionize the propellant. These electron bombardment processes can limit the overall efficiency of these electrostatic thrusters, particularly when operating at high thrust-to-power (T/P), because they use much more than the theoretical minimum amount of energy required to create each ion. Helicon sources are widely known to create ions much more efficiently than dc ion sources. Hall thrusters are typically built in an annular geometry to maximize the fraction of the propellant that travels through the area where Hall acceleration may occur. Although most previous helicon experiments have studied helicons in a cylindrical geometry, previous work has also demonstrated the operation of an annular helicon source [19]. Thus, it 
has been suggested that an annular helicon plasma source connected to a Hall acceleration stage could make the most efficient use of the electrical power available to a thruster operating at high T/P [20,21].

The helicon Hall thruster (HHT) is a two-stage thruster designed to use the efficient ion production qualities of an annular helicon plasma source with the acceleration mechanism of a Hall thruster. In particular, the HHT was constructed to investigate whether the inclusion of a radio frequency (RF) ionization stage could increase the overall efficiency of a Hall thruster in a high T/P, low specific impulse operating regime. The performance of the HHT was measured in the University of Michigan's Plasmadynamics and Electric Propulsion Laboratory (PEPL) during the summer of 2010. Although the results from the 2010 experiment were preliminary, the thrust measurements suggested that the HHT performance could be improved when higher levels of RF power were used [8]. A follow-on study was performed during the summer of 2011 with an improved RF power delivery system and thrust stand electromagnetic interference (EMI) mitigation scheme to confirm the results from 2010. During the follow-on test, the performance of the HHT operating with argon and nitrogen propellant was also measured. This report presents the results of the follow-on test.

\section{Methodology}

There are many ways to break down the total efficiency of a Hall thruster into component quantities [22,23]. These components are determined by thruster telemetry, performance measurements, and probe diagnostics and they can reveal the physical nature of thruster inefficiencies. This section outlines the efficiency architecture used to evaluate the performance of the HHT.

\section{A. Single-Stage Efficiency}

The total efficiency of a thruster is simply the power of the thrustproducing component of the exhaust divided by the total electrical power consumed by the thruster, as presented in Eq. (1). In laboratory model Hall thrusters, such as the HHT, the magnetic circuit design is generally not optimized for power consumption, and so the magnet power efficiency is separated accordingly. In addition, the cathode is not always optimized as it would be on a flight model thruster, so the cathode effects are also separated. The results of this breakdown allow the discharge or anode efficiency to be individually examined, as shown in Eq. (2)

$$
\begin{gathered}
\eta_{t}=\frac{P_{\text {thrust }}}{P_{\text {elec }}}=\frac{\frac{1}{2} \dot{m} v_{\text {axial }}^{2}}{P_{d}+P_{\text {mag }}} \\
\eta_{t}=\frac{\frac{1}{2} \dot{m}_{a} v_{\text {axial }}^{2}}{P_{d}}\left(1+\frac{\dot{m}_{c}}{\dot{m}_{a}}\right) \frac{1}{\left(1+\frac{P_{\text {mag }}}{P_{d}}\right)}=\eta_{a} \eta_{c} \eta_{\mathrm{mag}}=\eta_{d} \eta_{\mathrm{mag}} \\
\eta_{d}=E_{1} E_{2}=\left[\frac{\frac{1}{2}(T / \dot{m})^{2}}{V_{d}(\mathcal{F} / \mathcal{M})}\right]\left[\frac{\dot{m} \mathcal{F}}{I_{d} \mathcal{M}}\right]=\left[\Phi_{P} \Psi_{B} \eta_{V}\right]\left[\eta_{I}\right]
\end{gathered}
$$

Brown et al. suggest that using the voltage exchange parameter, $E_{1}$, and the mass exchange parameter, $E_{2}$, can help elucidate the physical sources of inefficiency using only thruster telemetry and thrust measurements, as represented in Eq. (3) [23]. Any further efficiency analysis requires the use of probe diagnostics in the thruster exhaust plume.

\section{B. Two-Stage Efficiency}

The difference between single-stage and two-stage operation is that two-stage operation uses RF power to affect the discharge in the vicinity of the gas inlet manifold. This is accounted for in the efficiency architecture by separating the dc and RF components of electrical power in the discharge, as shown in Eq. (4)

$$
\eta_{d}=\frac{\frac{1}{2} \dot{m}_{a} v_{\mathrm{axial}}^{2}}{P_{\mathrm{dc}}+P_{r f}} \eta_{c}=\eta_{a} \frac{1}{\left(1+\frac{P_{\mathrm{rf}}}{P_{\mathrm{dc}}}\right)} \eta_{c}=\eta_{a} \eta_{r f} \eta_{c}
$$

This definition of RF efficiency is consistent with the single-stage architecture, because $\eta_{\mathrm{rf}}=1$ when zero RF power is used. It also means that the exchange parameters can retain their definition from Eq. (3). This allows the effect of the RF power on thruster performance characteristics to be examined through the exchange parameters. To evaluate the net effect of RF power on propulsive efficiency, however, the RF efficiency must also be included.

\section{Apparatus}

\section{A. Facilitie}

This experiment was performed in the large vacuum test facility (LVTF) at PEPL. The LVTF is a cylindrical 6-m-diam by 9-m-long stainless clad steel chamber. Seven CVI TM-1200 nude cryopumps evacuate the LVTF at a combined pumping speed of 500, $0001 / \mathrm{s}$ on air or $245,0001 / \mathrm{s}$ on xenon. At the facility pressures measured in this experiment, neutral mean free paths for argon and nitrogen were always greater than $10 \mathrm{~m}$. At the highest flow rate and lowest voltage xenon conditions, the mean free path for charge exchange may have been shorter than $6 \mathrm{~m}$.

\section{B. Thruster}

The HHT is a two-stage thruster, with an RF ionization first stage and a Hall acceleration second stage. In the first stage, a loop antenna is employed with an axially directed magnetic field just downstream of the propellant distributor, as shown in Fig. 1.

The axial magnetic field and loop antenna are designed to excite annular helicon wave modes in the upstream part of the discharge channel. Specific magnetic field magnitude information is proprietary, and is excluded from this article. The second stage uses auxiliary electrodes as anodes together with a radial magnetic field and an external hollow cathode to create a traditional Hall accelerator. During this experiment, the auxiliary anodes were not in place, and the propellant distributor was used as the Hall accelerator anode. For each operating condition (i.e., mass flow rate and discharge voltage), the current supplied to each magnet coil was held constant as RF power was increased from zero to its maximum. Thus, all two-stage measurements were taken with the same applied magnetic field as the single-stage measurements taken at the same flow rate and discharge voltage.

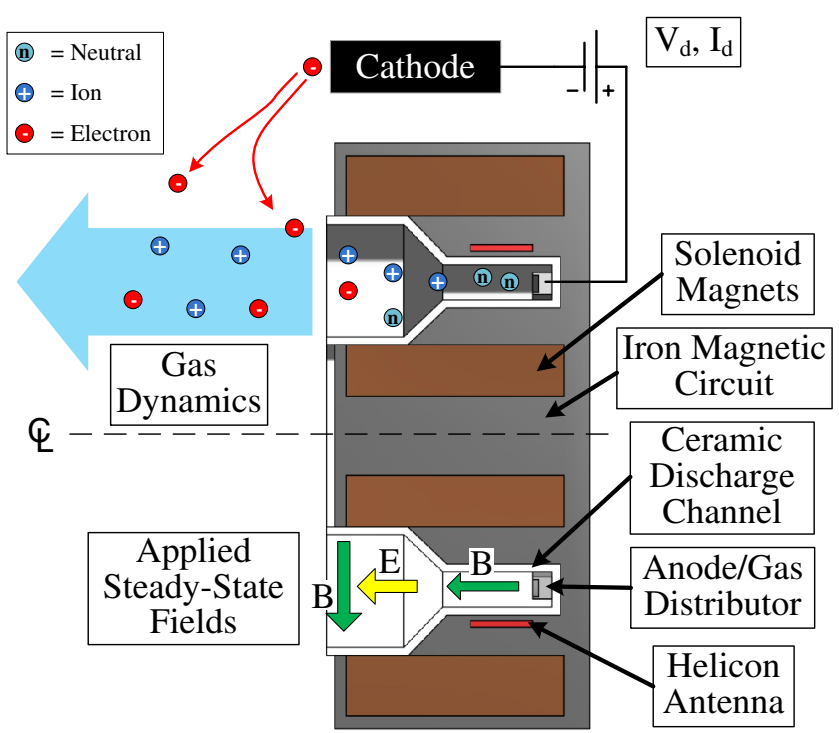

Fig. 1 Notional diagram of HHT operation. 


\section{RF Power System}

A Comdel CPS-3000 RF generator supplies RF power at a fixed frequency of $13.56 \mathrm{MHz}$. The CPS-3000 has a maximum output power of $3000 \mathrm{~W}$ at the standard $50 \Omega$ output impedance. An RG-213 coaxial cable transmits the RF power from the CPS-3000 output port to a hermetically sealed, HN-type bulkhead connector at the LVTF wall that acts as a vacuum feedthrough. Inside the LVTF, an RG-393 coaxial cable transmits the RF power from the feedthrough to the thrust stand platform. The final connection to the HHT matching network is made using a shorter length of RG-393 coaxial cable, and it is arranged to minimize forces on the thrust stand due to thermal expansion of the cable. Thus, a $50 \Omega$ system is maintained from the RF generator to the HHT matching network on the thrust stand.

The matching network is installed in the vacuum chamber to minimize the physical distance between the matching network output and the HHT antenna leads, and to increase the likelihood that the RF power measurements represent the actual power that is being delivered to the plasma. The matching network is in an L-type configuration, and two dc motors tune the two vacuum variable capacitors. The dc motors are manually controlled from outside the vacuum chamber by using a tethered remote control box.

A Werlatone $-60 \mathrm{~dB}$ dual directional coupler rated to $10 \mathrm{~kW}$ of power at 2-32 MHz (model\# C5389-32) is used to determine the RF power in the system. The frequency response of the directional coupler is calibrated using an Agilent E5071C network analyzer, and it is shown to be a constant $-60 \mathrm{~dB}$ over the range of 1-60 MHz. Directivity for both the forward and reflected coupling port is a constant $-30 \mathrm{~dB}$ over the same frequency range. The dual directional coupler was placed in the vacuum chamber and connected directly inline at the matching network RF power input port. The forward and reflected voltage signals are observed both with an Agilent DSOX3024A oscilloscope and with a spectrum analyzer to monitor the health and general behavior of the RF power delivery system. For each data point employing RF power, the oscilloscope records $2 \mathrm{~ms}$ of forward and reflected voltage waveform data sampled at $2 \mathrm{GSa} / \mathrm{s}$, and postprocessing is used to determine the forward and reflected power.

To determine the uncertainty in the RF power measurements from the directional coupler, the procedure outlined by Garvin et al. [24] was followed. The oscilloscope manual lists a voltage measurement uncertainty of $\pm 2.25 \%$. The directional coupler response was calibrated with a network analyzer, and each voltage measurement error is conservatively rounded to $\pm 4 \%$ relative uncertainty. The observed voltage reflection coefficient ranged from 0.0 to 0.4 . Thus, the uncertainty for each RF power measurement is conservatively estimated to be between $\pm 4 \%$ and $\pm 11 \%$.

\section{Thrust Stand}

The inverted pendulum, null-type thrust stand at PEPL is very similar to that described by $\mathrm{Xu}$ and Walker [25], except there is no piezoelectric control of the inclination. During this experiment, the thrust stand is operated as a displacement-type thrust stand to allow a simple and reliable check for EMI. When operated in the displacement-type configuration, an electromagnetic damper coil eliminates high-frequency oscillations in the position of the thrust stand, and a steady thrust displaces the equilibrium position.

The EMI check is as follows: the thrust stand spring is replaced by a solid bar of mica material, so that the thrust stand equilibrium position is locked in one place. The thruster is then operated normally with and without RF power, and if any change in the position is observed during operation, the change is noted to be a result of EMI. Although the unmodified experimental setup exhibited signs of EMI, including increased noise and dc offsets on telemetry and performance signals, the effect of the RF plasma on the thrust stand was eventually eliminated by implementing an EMI mitigation scheme similar to that described by Kieckhafer and Walker [26]. Observations in this experiment indicated that the most effective reduction of EMI occurred with the application of split-core ferrite beads to all electrical cables leading to the thruster and thrust stand. It is extremely important, however, that the proper "mix" of ferrite material is chosen so that the impedance of each electrical cable is maximized at the RF driving frequency.

Thrust stand calibrations were carried out at the beginning and end of each day of testing. Based on the variation in the calibration slope and the resolution of the data acquisition system, the absolute thrust measurement uncertainty is conservatively estimated to be $\pm 2.5 \%$ during this experiment.

\section{E. Faraday Probe}

A nude Faraday probe is used to measure the ion current density in the HHT exhaust plume. This Faraday probe is described in detail by Liang and Gallimore [27], and is modeled after the nested Faraday probe design described by Brown and Gallimore [28]. The Faraday probe is mounted to a rotation stage such that it can move in an arc about the HHT exit plane. To take data, the guard ring and both collectors are biased at $-30 \mathrm{~V}$ with respect to facility ground into ion saturation. The current drawn by the inner collector is recorded as the probe is swept between -90 and $90 \mathrm{deg}$, where $0 \mathrm{deg}$ is along the thruster centerline.

The total ion beam current is determined by assuming that the exhaust plume is axisymmetric and integrating the Faraday probe collected current data according to Eq. (5). The effective collector area includes all correction factors described by Brown [29]. The axial component of the beam current is calculated from Eq. (6), and following from the efficiency architecture of Brown et al. [23] , the beam divergence efficiency is determined by Eq. (7)

$$
\begin{gathered}
I_{\text {beam }}=2 \pi r^{2} \int_{0}^{\pi / 2} \frac{I_{c}(\theta)}{A_{c, \text { eff }}} \sin \theta \mathrm{d} \theta \\
I_{\text {axial }}=2 \pi r^{2} \int_{0}^{\pi / 2} \frac{I_{c}(\theta)}{A_{c, \text { eff }}} \sin \theta \cos \theta \mathrm{d} \theta \\
\Psi_{B}=\left(\frac{I_{\text {axial }}}{I_{\text {beam }}}\right)^{2}
\end{gathered}
$$

Following the analysis by Brown [29], and because Faraday probe data for each thruster operating condition are taken at one downstream distance and one facility backpressure, the uncertainty in the total and axial ion beam current measurements are estimated to be $\pm 6 \%$ and $\pm 10 \%$, respectively.

\section{F. Retarding Potential Analyzer}

The ion energy distribution funtion (IEDF) is measured with a retarding potential analyzer (RPA) that has been previously used to measure plasma properties in a helicon plasma source [30], as well as in Hall thruster plumes [6,22] at PEPL. The RPA is based on a design by the U.S. Air Force Research Laboratory, and is described in detail by Hofer [22]. In this experiment, the electron repelling grid is biased to a constant $-30 \mathrm{~V}$ potential with respect to facility ground by a Kikusui PAD 55-6L power supply. The ion retarding grid is swept from 0 to $500 \mathrm{~V}$ above ground with a Keithley 2410 sourcemeter to progressively filter out higher energy ions, and a Keithley 6485 picoammeter measures the current to the collector at each ion retarding voltage. The IEDF is directly proportional to the first derivative of the measured current-voltage characteristic, and the ion retarding grid voltage at the maximum in the IEDF curve is the "most probable ion energy."

The RPA is mounted to a linear translation stage with the floating grid located approximately $6 \mathrm{~m}$ downstream of the thruster exit plane. A langmuir probe is also mounted to the translation stage so that both RPA and langmuir probe data could be taken at the same position. The plasma potential is determined by the peak in the first derivative of the langmuir probe current-voltage characteristic, and the voltage utilization efficiency is calculated from the RPA and langmuir probe data according to Eq. (ㅁ) 


$$
\eta_{V}=\frac{V_{\mathrm{mp}}-V_{p}}{V_{d}}
$$

Previous studies using this particular RPA in Hall thruster plumes have estimated the uncertainty in the most probable potential measurement to be $\pm 10 \mathrm{~V}[22,29]$. The uncertainty can be attributed to broadening of the peak due to the RPA's large acceptance halfangle (approximately $45 \mathrm{deg}$, and the effects of smoothing and numerical differentiation of the raw RPA data.

\section{Results}

The performance of the HHT was measured on xenon, argon, and nitrogen propellants with and without the RF stage operating. When operating with argon and nitrogen, research-grade xenon was used for cathode flow. The HHT was constructed to investigate whether an RF ionization stage could increase the efficiency of a Hall truster operating in a low specific impulse regime, and so this experiment focused on low discharge voltage, xenon operating conditions. The argon and nitrogen flow rates were chosen such that the number flow rate of gas molecules emanating from the gas distributor was in the range covered by the xenon conditions. Table 1 summarizes the HHT operating conditions that were analyzed during this experiment, with the plume measurements column indicating when probes were used to make measurements in single-stage mode and/or while the RF stage was operating. The corrected LVTF background pressure during HHT xenon operation was measured to be $4.6 \times 10^{-6}$ to $1.5 \times 10^{-5}$ torr. During argon and nitrogen operation, the corrected LVTF background pressure was measured to be $3.9 \times 10^{-6}$ and $3.6 \times 10^{-6}$ torr, respectively.

\section{A. Single-Stage Operation}

Results of the HHT single-stage performance test are shown in Figs. 2 and 3 . Figure 2 shows the expected result that thrust increases with discharge voltage and with mass flow rate, regardless of the propellant used. Figure 3 shows that the T/P for the HHT operating with xenon is between $\overline{6} 0$ and $72 \mathrm{mN} / \mathrm{kW}$. When operating with xenon propellant, T/P tends to increase with increasing discharge voltage, and is maximized at the intermediate anode mass flow rates. Although argon and nitrogen operating conditions were at higher discharge voltages, T/P is only 30 and $21 \mathrm{mN} / \mathrm{kW}$, respectively.

To investigate the loss mechanisms of the HHT operating on alternative propellants, the exchange parameters are plotted as a function of anode mass flow rate. The exchange parameters are calculated only from thrust measurements and thruster telemetry. Thus, an analysis of the exchange parameter trends may provide insight into the physics of the HHT operation without requiring probe measurements. Because the cathode flow is xenon, the weighted average molar mass of the cathode and anode flow is used in the exchange parameter calculations.

Figure 4 shows that $E_{1}$ increases with anode mass flow rate and voltage. Although the nitrogen and argon operating conditions were at relatively higher voltages, $E_{1}$ remained fairly low, comparable to the $100 \mathrm{~V}, 15 \mathrm{mg} / \mathrm{s}$ xenon case. It appears that the nitrogen operating

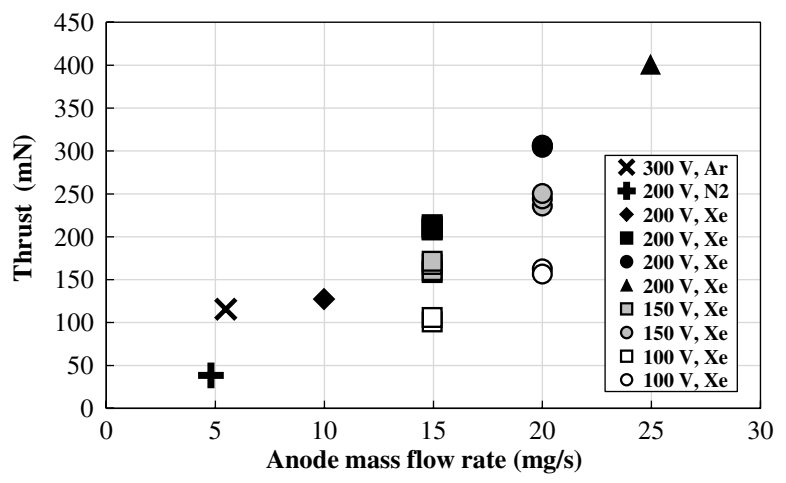

Fig. 2 Single-stage thrust vs anode mass flow rate.

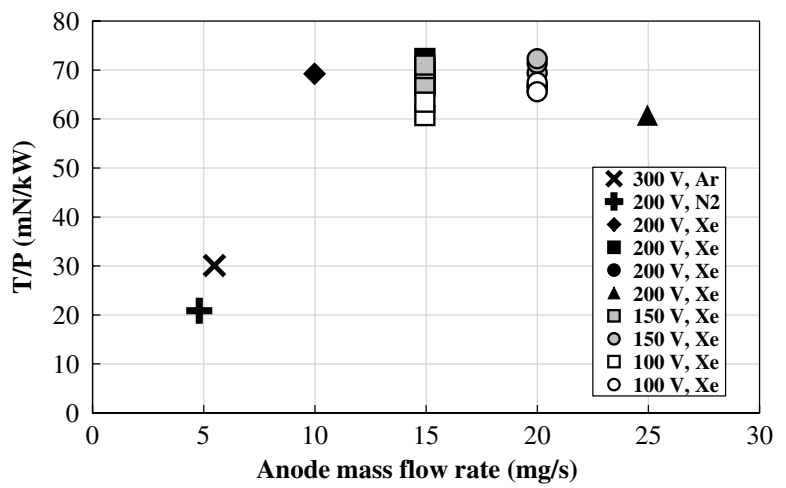

Fig. 3 Single-stage T/P vs anode mass flow rate.

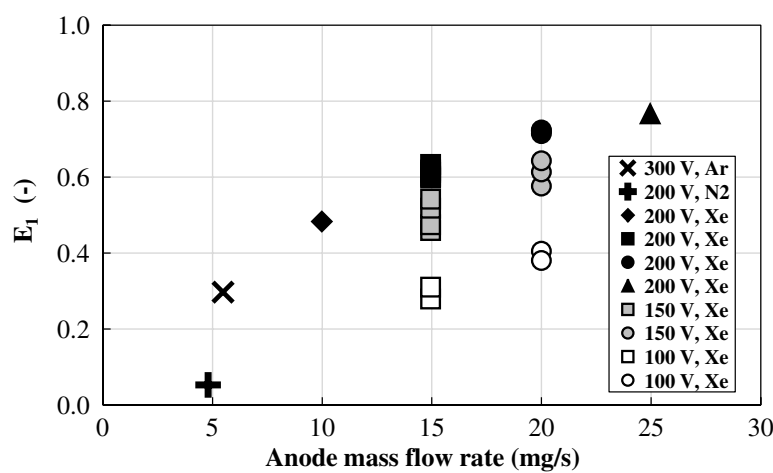

Fig. 4 Voltage exchange parameter plotted vs anode mass flow rate.

point follows the trend for 200 Voperation with xenon, and that it may simply be the low mass flow rate that explains the low value of $E_{1}$. However, it appears that the argon point may have a lower $E_{1}$ than a $300 \mathrm{~V}$ operating condition with an equivalent xenon mass flow rate. Figure $\underline{5}$ shows that $E_{2}$ for xenon operation decreases with anode

Table 1 Summary of HHT operating conditions

\begin{tabular}{lccccc}
\hline \hline Propellant & Anode flow rate, $\mathrm{mg} / \mathrm{s}$ & Discharge voltage, $\mathrm{V}$ & RF power range, $\mathrm{W}$ & Cathode flow fraction & Plume measurements \\
\hline xenon & 10.0 & 200 & $0-1036$ & $7.1 \%$ & $1 \mathrm{~s}$ \\
xenon & 14.9 & 100 & $0-1028$ & $5.0 \%$ & $1 \mathrm{~s}$ \\
xenon & 14.9 & 150 & $0-1041$ & $5.0 \%$ & $1 \mathrm{~s}$ \\
xenon & 14.9 & 200 & $0-1032$ & $5.0 \%$ & $1 \mathrm{~s}$ \\
xenon & 20.0 & 100 & $0-994$ & $5.0 \%$ & $1 \mathrm{~s}$ and $2 \mathrm{~s}$ \\
xenon & 20.0 & 150 & $0-1205$ & $5.0 \%$ & $1 \mathrm{~s}$ and $2 \mathrm{~s}$ \\
xenon & 20.0 & 200 & $0-986$ & $5.0 \%$ & $1 \mathrm{~s}$ \\
xenon & 25.0 & 200 & $0-613$ & $7.0 \%$ & - \\
argon & 5.95 & 300 & $0-270$ & $16.8 \% \%^{\circ}$ & $1 \mathrm{~s}$ and $2 \mathrm{~s}$ \\
nitrogen & 2.60 & 200 & $0-302$ & $38.4 \%$ & $1 \mathrm{~s}$ \\
\hline \hline
\end{tabular}

${ }^{\mathrm{a}} 1 \mathrm{~s}=$ single-stage operation, $2 \mathrm{~s}=$ two-stage operation.

${ }^{\mathrm{b}}$ Cathode flow was $1.0 \mathrm{mg} / \mathrm{s}$ of xenon during operation with argon and nitrogen anode flow. 


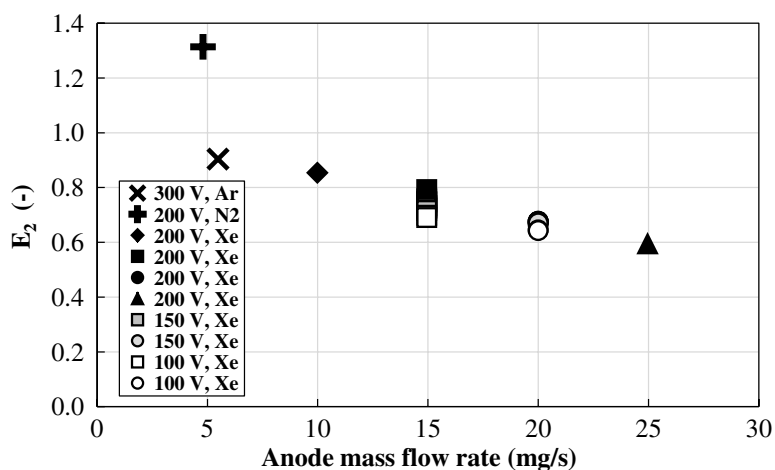

Fig. 5 Mass exchange parameter plotted vs anode mass flow rate.

mass flow rate, and is not significantly affected by discharge voltage. In contrast to $E_{1}, E_{2}$ for argon appears to follow the trend for xenon, whereas $E_{2}$ for nitrogen is much lower; however, it is unclear whether or not the behavior of a xenon operating point with an equivalently low anode mass flow rate would follow the nitrogen results. Equation (3) states that $E_{2}$ is equivalent to current utilization in the efficiency architecture used here, and so the lower efficiency of the nitrogen operating point may be partly explained by a low current utilization.

The beam divergence efficiency is calculated from the nude Faraday probe data, and the results are shown in Fig. 6. Previous experiments have shown that beam divergence efficiency increases with increasing discharge voltage, and weakly increases with increasing anode flow rate [23]; however, Fig. 6 shows that the HHT's beam divergence for the $200 \mathrm{~V}$ nitrogen condition is equivalent to the $100 \mathrm{~V}$ xenon conditions, and the divergence of the $300 \mathrm{~V}$ argon condition is nearly the same as the $150 \mathrm{~V}$ xenon conditions. This result suggests that the beam divergence efficiency is affected by propellant gas species, and not simply mass flow rate. This finding is consistent with the results seen by Linnell [31], who showed that krypton propellant consistently had a lower beam divergence efficiency than xenon for equivalent operating conditions in the NASA-173Mv1. Although the beam divergence efficiency is lower for the nitrogen and argon operating points, divergence alone does not completely explain the lower values of $E_{1}$ seen in both.

Results calculated from the RPA and langmuir probe data are plotted in Fig. 7. The data show that argon and nitrogen voltage utilization efficiency does not have a significant deficit compared to xenon. The nitrogen operating point appears to fall in line with the $200 \mathrm{~V}$ xenon trend, and the slightly higher voltage utilization of the argon operating point may simply be explained by the fact that voltage utilization tends to increase with increasing discharge voltage. Discharge voltage therefore remains the dominant factor in determining voltage utilization, further evidenced by the lower voltage utilization of the $100 \mathrm{~V}$ xenon operating points.

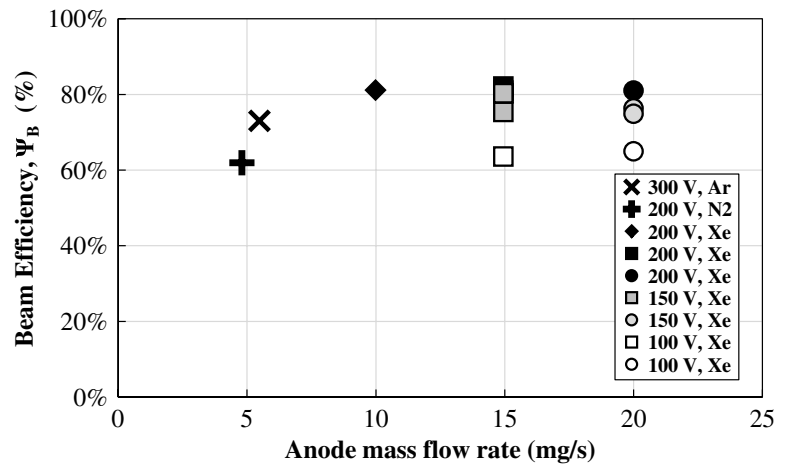

Fig. 6 Beam divergence efficiency vs anode mass flow rate.

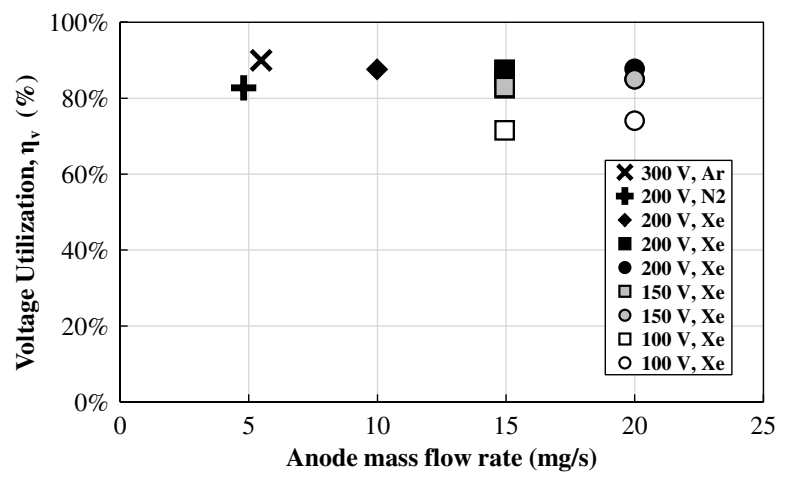

Fig. 7 Voltage utilization efficiency plotted vs anode mass flow rate.

The propellant utilization efficiency can be inferred from the data plotted in Figs. 4-7 together with Eq. (3). The inferred propellant utilization efficiency is plotted in Fig. 8, which shows that propellant utilization of the HHT operating on argon and nitrogen was much lower than when the HHT operated on xenon. This result again agrees with the results seen by Linnell [31], who states that "the beam divergence accounts for a loss equally important as propellant utilization" when referring to operation with krypton vs xenon propellant.

Diatomic nitrogen and argon have nearly the same first ionization energy, 15.58 and $15.76 \mathrm{eV}$, respectively, compared to $12.13 \mathrm{eV}$ for xenon [32]. However, rotational and vibrational energy excitation can sink energy away from a nitrogen plasma, but not an argon or a xenon plasma. The decrease in propellant utilization efficiency for argon, and especially for nitrogen, is disproportionately larger than the $30 \%$ difference in ionization energy when compared to xenon. Although the low efficiencies of the $100 \mathrm{~V}$ xenon operating conditions are spread across mulitple loss mechanisms, the loss for argon and nitrogen is primarily from the lower propellant utilization. This may be due in part to the lower molecular weight of argon and nitrogen and a smaller ionization cross section, which cause a shorter residence time in the discharge channel and a lower probability of ionization of the propellant. The significantly lower value for nitrogen may be explained by the fact that a nitrogen molecule, with a bond energy of $9.8 \mathrm{eV}$, can split into a pair of nitrogen atoms, which have a $14.53 \mathrm{eV}$ first ionization energy [32]. Thus, dissociation of nitrogen can sink energy away from the discharge, and transform the propellant into species that require even more energy to ionize.

\section{B. Two-Stage Operation}

During two-stage operation, the RF ionization stage was powered in the attempt to increase HHT anode efficiency at high T/P operating points. As the RF power is increased from zero to its maximum, the current supplied to each solenoid coil that produces the magnetic field is held constant. This is done because the magnets for the helicon stage were seen to act as trim coils for the Hall stage when no RF

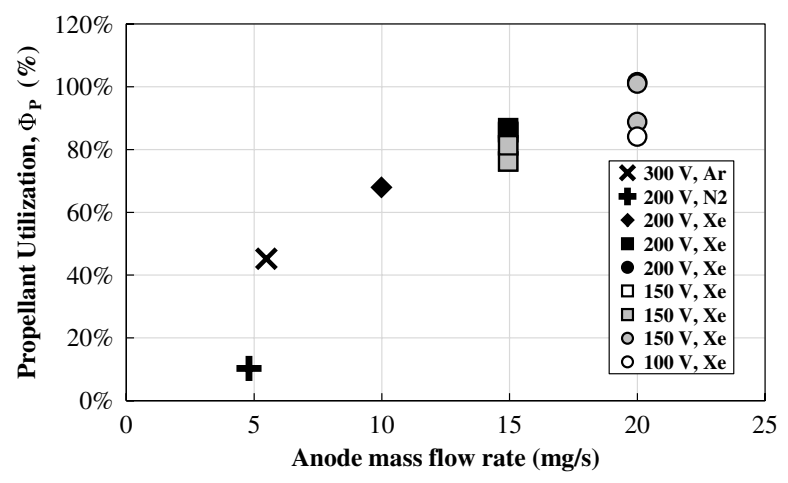

Fig. 8 Inferred propellant utilization efficiency vs anode mass flow rate. 


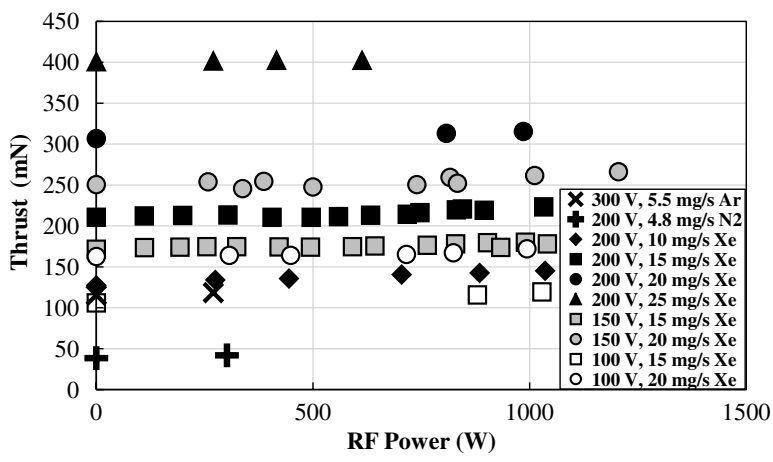

Fig. 9 Two-stage thrust vs RF power.

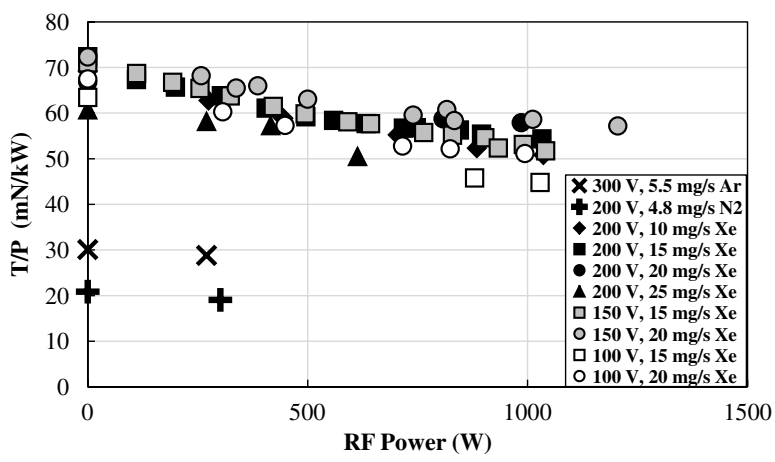

Fig. 10 Two-stage T/P, including both $\boldsymbol{P}_{\mathrm{dc}}$ and $\boldsymbol{P}_{\mathrm{rf}}$, vs RF power.

power was used. Figure 9 shows that thrust increased slightly with RF power on for most operating conditions; however, Fig. 10 shows that the rate of increase in thrust is always exceeded by the rate of increase in RF power, such that the overall T/P decreases with increasing RF power. The decreasing trend with RF power is also observed in the total anode efficiency, which includes RF efficiency, as shown in Fig. 11.

Because RF efficiency is defined separately from anode efficiency, the exchange parameters can be used to investigate how the RF power

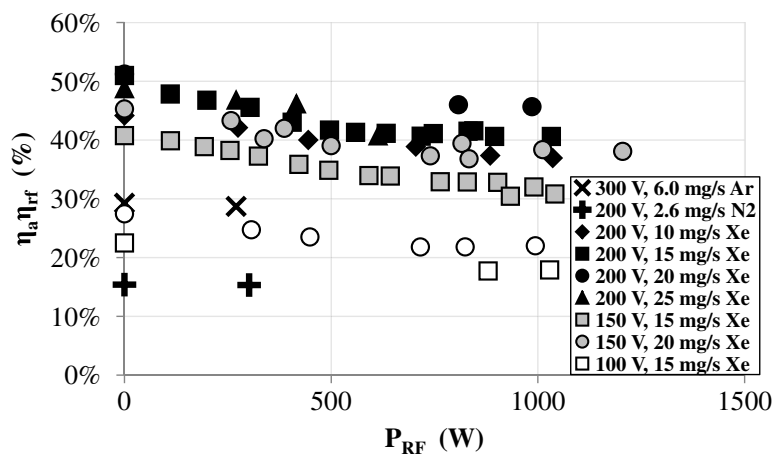

Fig. 11 Total anode efficiency vs RF power.

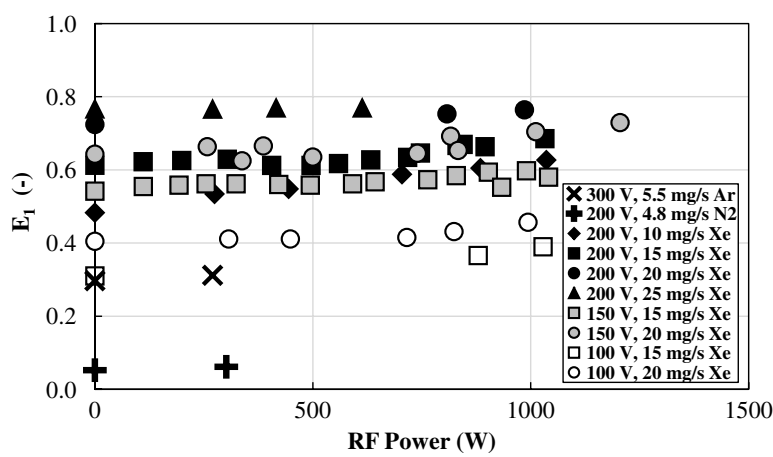

Fig. 12 Voltage exchange parameter plotted vs RF power.

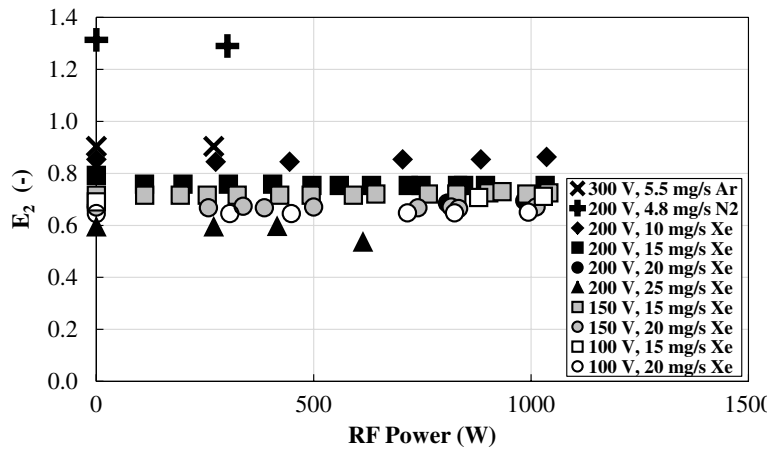

Fig. 13 Mass exchange parameter plotted vs RF power.

affects the overall thruster behavior. The exchange parameters are plotted against RF power in Figs. 12 and 13 . Figure 12 shows that $E_{1}$ increases slightly with RF power. The trend decreases with increasing anode mass flow rate for xenon operating conditions, with RF power having no effect on $E_{1}$ for the $25 \mathrm{mg} / \mathrm{s}$ xenon conditions. Only one operating point each for argon and nitrogen with RF power were performed, but both showed an increase in $E_{1}$. Current utilization, which is equal to $E_{2}$, is not significantly affected by RF power, as shown in Fig. 13, except that there is a sudden drop for the $25 \mathrm{mg} / \mathrm{s}$ xenon operating point at about $600 \mathrm{~W}$.

Faraday probe results plotted in Fig. 14 show that RF power has no significant effect on beam divergence efficiency for the conditions that were measured. Figure 15 plots voltage utilization efficiency as a function of RF power, and shows a somewhat surprising result that voltage utilization tends to decrease with increasing RF power. The probe results, together with Figs. 12 and $\underline{13}$, indicate that the RF power indeed increased propellant utilization efficiency, at least for the argon operating condition and for the $20 \mathrm{mg} / \mathrm{s}$ xenon operating conditions at 100 and $150 \mathrm{~V}$.

Note that the coupling mode of the RF stage to the plasma was not directly measured. Although the HHT was designed to excite helicon waves in the plasma, it cannot be concluded that the HHT was operated in a helicon mode. Thus, this experiment did not necessarily

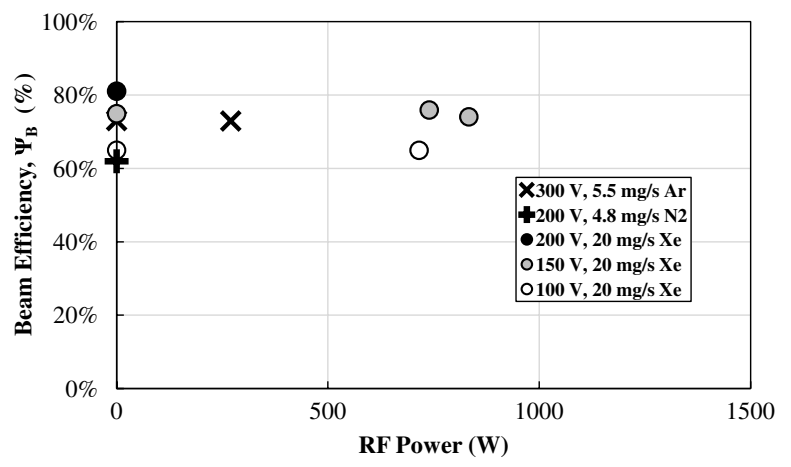

Fig. 14 Beam divergence efficiency vs RF power.

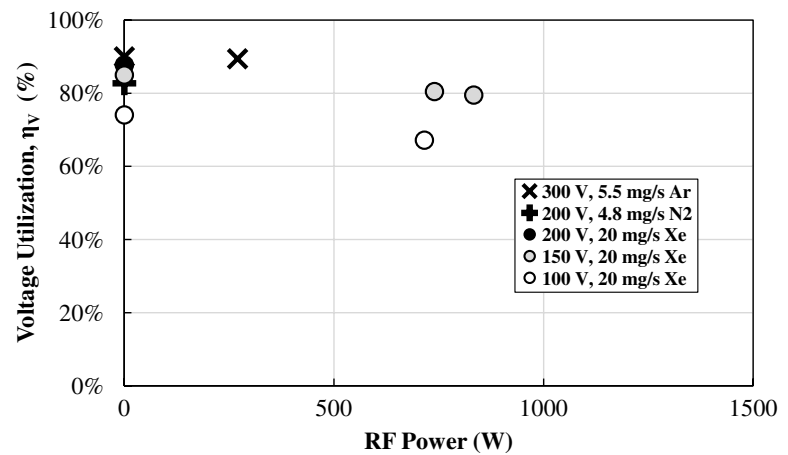

Fig. 15 Voltage utilization vs RF power. 
operate the HHT at the optimal conditions for the RF stage. Despite this fact, the results suggest that the RF stage may have increased the propellant utilization of the HHT. It is therefore possible that further experiments with the HHT, or a different thruster, incorporating a more optimized annular helicon stage may show that an RF stage is capable of providing a net performance gain.

\section{Conclusions}

The performance of the HHT operating in both single-stage and two-stage modes with argon, nitrogen, and xenon propellant was measured at the University of Michigan. Faraday probe, RPA, and langmuir probe measurements in the far-field plume characterized the HHT beam divergence efficiency and voltage utilization. Beam divergence efficiency for nitrogen and argon propellant is lower than that expected for xenon at an equivalent discharge voltage and anode mass flow rate. Voltage utilization for argon and nitrogen is not significantly reduced, and so it is deduced that propellant utilization efficiency is also lower than that for xenon. Current utilization is a major source of anode inefficiency for nitrogen propellant, but not for argon. During two-stage operation, thrust is observed to increase slightly with RF power, except at the $25 \mathrm{mg}$ /s xenon propellant operating condition; however, T/P and total anode efficiency both consistently decrease with increasing RF power. The exchange parameters taken with limited probe results suggest that propellant utilization likely increases with RF power, but the increase is not sufficient to overcome the reduced efficiency due to the use of RF power. Further experiments are required to determine whether any optimized RF stage can provide a net gain to the performance of a Hall thruster.

\section{Acknowledgments}

This work was performed by ElectroDynamic Applications, Inc. as part of the Small Business Innovative Research program, under Air Force Contract FA9300-08-C-1007. The authors would like to acknowledge their partners at Aerojet, Andy Hoskins and Rafael Martinez. A. Shabshelowitz would also like to thank Alex Kieckhafer and Mitchell Walker of Georgia Institute of Technology for their helpful discussions regarding EMI, and Anthony Sebastian from the Lurie Nanofabrication Facility at the University of Michigan for his advice regarding RF hardware.

\section{References}

[1] Zhurin, V. V., Kaufman, H. R., and Robinson, R. S., "Physics of Closed Drift Thrusters," Plasma Sources Science and Technology, Vol. 8, No. 1, 1999.

doi:10.1088/0963-0252/8/1/021

[2] Goebel, D. M., and Katz, I., Fundamentals of Electric Propulsion: Ion and Hall Thrusters, Wiley, Hoboken, NJ, 2008, Chap. 9.

[3] Mikellides, I. G., Katz, I., Hofer, R. R., Goebel, D. M., de Grys, K., and Mathers, A., "Magnetic Shielding of the Acceleration Channel Walls in a Long-Life Hall Thruster," AIAA Paper 2010-6942, July 2010.

[4] Makela, J. M., Washeleski, R. L., Massey, D. R., King, L. B., and Hopkins, M. A., "Development of a Magnesium and Zinc Hall-Effect Thruster," 31 st International Electric Propulsion Conference, IEPC Paper 2009-107, Sept. 2009.

[5] Szabo, J., Robin, M., Duggan, J., and Hofer, R. R., "Light Metal Propellant Hall Thrusters," 31st International Electric Propulsion Conference, IEPC Paper 2009-138, Sept. 2009.

[6] Liang, R., and Gallimore, A. D., "Constant-Power Performance and Plume Properties of a Nested-Channel Hall-Effect Thruster," 32nd International Electric Propulsion Conference, IEPC Paper 2011-030, Sept. 2011.

[7] Florenz, R., Gallimore, A. D., and Peterson, P. Y., "Developmental Status of a 100-kW Class Laboratory Nested Channel Hall Thruster," 32nd International Electric Propulsion Conference, IEPC Paper 2011246, Sept. 2011.

[8] Peterson, P. Y., Massey, D. R., Shabshelowitz, A., Shastry, R., and Liang, R., "Performance and Plume Characterization of a Helicon Hall Thruster," 32nd International Electric Propulsion Conference, IEPC Paper 2011-269, Sept. 2011.
[9] Kamhawi, H., Manzella, D., Pinero, L., Haag, T., Mathers, A., and Liles, H., "In-Space Propulsion High Voltage Hall Accelerator Development Project Overview," AIAA Paper 2010-5282, 2010.

[10] Boswell, R. W., and Chen, F. F., "Helicons-The Early Years," IEEE Transactions on Plasma Science, Vol. 25, No. 6, 1997, pp. 12291244. doi:10.1109/27.650898

[11] Chen, F. F., and Boswell, R. W., "Helicons-The Past Decade," IEEE Transactions on Plasma Science, Vol. 25, No. 6, 1997, pp. 1245-1257. doi:10.1109/27.650899

[12] Pottinger, S., Lappas, V., Charles, C., and Boswell, R., "Performance Characterization of a Double Layer Thruster Using Direct Thrust Measurements," Journal of Applied Physics D: Applied Physics, Vol. 44, No. 23, 2011, p. 235201. doi:10.1088/0022-3727/44/23/235201

[13] Shabshelowitz, A., and Gallimore, A. D., "Divergence Angle of Ion Beams Emanating from an Immersed Radiofrequency Plasma Source," 32nd International Electric Propulsion Conference, IEPC Paper 2011-166, Wiesbaden, Germany, Sept. 2011.

[14] Palmer, D., Walker, M. L. R., Manente, M., Carlsson, J., Bramanti, C., and Pavarin, D., "Performance Analysis of a Low-Power Helicon Thruster," AIAA Paper 2008-4925, July 2008.

[15] Pavarin, D., Ferri, F., Manente, M., Curreli, D., Güçlü, Y., Melazzi, D., Rondini, D., Suman, S., Carlsson, J., Bramanti, C., Ahedo, E., Lancellotti, V., Katsonis, K., and Markelov, G., "Design of a $50 \mathrm{~W}$ Helicon Plasma Thruster," 31st International Electric Propulsion Conference, IEPC Paper 2009-205, Sept. 2009.

[16] Longmier, B. W., Cassady, L. D., Ballenger, M. G., Carter, M. D., Chang-Díaz, F. R., Glover, T. W., Ilin, A. V., McCaskill, G. E., Olsen, C. S., and Squire, J. P., "VX-200 Magnetoplasma Thruster Performance Results Exceeding Fifty-Percent Thruster Efficiency," Journal of Propulsion and Power, Vol. 27, No. 4, 2011, pp. 915-920. doi:10.2514/1.B34085

[17] Nakamura, T., Yokoi, K., Nishida, H., Shinohara, S., Funaki, I., Matsuoka, T., Tanikawa, T., Hada, T., Shamrai, K. P., and Rudenko, T. S., "Experimental Investigation of Plasma Acceleration by Rotating Electric Field for Electrodeless Plasma Thruster," 32nd International Electric Propulsion Conference, IEPC Paper 2011-279, Sept. 2011.

[18] Slough, J., Kirtley, D., and Weber, T., "Pulsed Plasmoid Propulsion: The ELF Thruster," 31st International Electric Propulsion Conference, IEPC Paper 2009-265, Sept. 2009.

[19] Palmer, D. D., and Walker, M. L. R., "Operation of an Annular Helicon Plasma Source," Journal of Propulsion and Power, Vol. 25, No. 5, 2009, pp. 1013-1019. doi: $10.2514 / 1.41403$

[20] Beal, B. E., Gallimore, A. D., Morris, D. P., Davis, C., and Lemmer, K. M., "Development of an Annular Helicon Plasma Source for Electric Propulsion Applications," AIAA Paper 2006-4841, July 2006.

[21] Yano, M., and Walker, M. L., "Plasma Ionization by Annularly Bounded Helicon Waves," Physics of Plasmas, Vol. 13, 2006, p. 063501-1-5. doi: $10.1063 / 1.2207125$

[22] Hofer, R. R., "Development and Characterization of a High-Efficiency, High-Specific Impulse Xenon Hall Thruster," Ph.D. Dissertation, University of Michigan, Ann Arbor, MI, 2004.

[23] Brown, D. L., Larson, C. W., Beal, B. E., and Gallimore, A. D., "Methodology and Historical Perspective of a Hall Thruster Efficiency Analysis," Journal of Propulsion and Power, Vol. 25, No. 6, 2009, pp. $1163-1177$. doi:10.2514/1.38092

[24] Garvin, C., Grimard, D., Grizzle, J., and Gilchrist, B. E., "Measurement and Error Evaluation of Electrical Parameters at Plasma Relevant Frequencies and Impedances," Journal of Vacuum Science and Technology A: Vacuum, Surfaces, and Films, Vol. 16, No. 2, pp. 595-606. doi: $10.1116 / 1.581098$

[25] Xu, K., and Walker, M. L. R., "High-Power, Null-Type, Inverted Pendulum Thrust Stand," Review of Scientific Instruments, Vol. 80, No. 5, 2009, p. 055103. doi:10.1063/1.3125626

[26] Kieckhafer, A. W., and Walker, M. L. R., "RF Power System for Thrust Measurements of a Helicon Plasma Source," Review of Scientific Instruments, Vol. 81, No. 7, 2010, p. 075106. doi:10.1063/1.3460263

[27] Liang, R., and Gallimore, A. D., "Far-Field Plume Measurements of a Nested-Channel Hall-Effect Thruster," AIAA Paper 2011-1016, Jan. 2011.

[28] Brown, D. L., and Gallimore, A. D., "Evaluation of Ion Collection Area in Faraday Probes," Review of Scientific Instruments, Vol. 81, No. 6, 
2010, p. 063504.

doi: $10.1063 / 1.3449541$

[29] Brown, D. L., "Investigation of Low Discharge Voltage Hall Thruster Characteristics and Evaluation of Loss Mechanisms," Ph.D. Dissertation, University of Michigan, Ann Arbor, MI, 2009.

[30] Lemmer, K. M., "Use of a Helicon Source for Development of a ReEntry Blackout Amelioration System," Ph.D. Dissertation, University of Michigan, Ann Arbor, MI, 2009.

[31] Linnell, J. A., "An Evaluation of Krypton Propellant in Hall Thrusters," Ph.D. Dissertation, University of Michigan, Ann Arbor, MI, 2007.
[32] Lias, S. G., "Ionization Energy Evaluation," NIST Chemistry WebBook, NIST Standard Reference Database Number 69, edited by Linstrom, P. J., and Mallard, W. G., National Institute of Standards and Technology, Gaithersburg, MD, 20899, http://webbook.nist.gov [retrieved May 31, 2012].

J. Blandino Associate Editor 